\title{
Residual effects of tracer in sequential double label deoxyglucose studies ${ }^{*}$
}

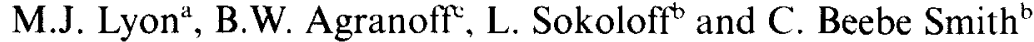 \\ "Department of Otolaryngology, State University of New York Health Science Center, Syracuse, NY (USA), "Laboratory of Cerebral Metabolism. \\ National Institute of Mental Health, U.S. Public Health Service, Department of Health and Human Services, Bethesda, MD (USA) and Neuroscience \\ Laboratory, Mental Health Research Institute, University of Michigan. Ann Arbor, MI (USA)
}

(Received 11 June 1992: Revised version received 19 August 1992; Accepted 24 August 1992)

Key words: Deoxyglucose; Double label autoradiography; Energy metabolism; Brain; CNS

The validity of sequential double label deoxyglucose (DG) determinations of local metabolic rate for glucose (IMR $\mathrm{glc}_{\mathrm{c}}$ ) was examined by quantifying the degree of trapping of residual first DG tracer during the second experimental period. One sciatic nerve was repetitively stimulated for 25 min. beginning either at the time of the DG injection or $25 \mathrm{~min}$ later. $\mathrm{IMR}_{\mathrm{gl}}$ in the ipsilateral dorsal horn of the lumbar spinal cord was found to be $105 \%$ and $56 \%$, respectively, greater than that of the contralateral unstimulated side. Attempts to lower the body burden of radioactive DG by exchange blood transfusion failed to reduce this delayed effect. These data indicate that residual effects of the first tracer could obscure possible differences in IMR $_{\text {gic }}$ between two sequential experimental states.

The deoxyglucose (DG) method for determination of local rates of glucose utilization ( $\mathrm{IMR}_{\mathrm{glc}}$ ) is used extensively to study regional brain responses to physiological, pharmacological and behavioral perturbations [14]. Because it was designed for use with quantitative autoradiography [15], the technique can measure $\mathrm{IMR}_{\mathrm{glc}}$ only once in each animal. The ability to measure $I M R_{\text {glc }}$ twice sequentially in the same animal [1] would allow a single animal to serve as its own control; experimental variance and the number of animals needed to obtain statistical significance could then be reduced. Furthermore, metabolic maps of the two conditions in the same brain sections would facilitate analysis of more subtle differences in anatomical localization of activated areas. Several groups $[4,7,12]$ have proposed the use of double label autoradiographic DG studies with ${ }^{3} \mathrm{H}$ - and ${ }^{14} \mathrm{C}$-labeled DG administered sequentially to the same animal with each injection temporally associated with a different experimental condition. The assumption underlying these double label measurements is that the $I \mathrm{MR}_{\mathrm{glc}}$ measured with each species of labeled DG reflects the condition of the animal during the experimental period immediately following the injection $[4,7]$. Only in the studies of Re-

Correspondence: C.B. Smith, Laboratory of Cerebral Metabolism. National Institute of Mental Health, Building 36, Room 1A-05, 9000 Rockville Pike, Bethesda, MD 20892 (USA). Fax: (1) (301) 4801668.

*These results were presented in part at the 21st Annual Meeting of the Society for Neuroscience in New Orleans, Louisiana, 1991 (Lyon et al., 1991). dies et al. [12] was there consideration of the effect of the second condition on the residue of the first tracer in the tissue; in these studies application of a mathematical correction based on tracer kinetic modeling was proposed.

The purpose of the present study was to determine quantitatively and by direct experiment the effects of the second experimental condition on the metabolic trapping of the first tracer still remaining in the animal while keeping the total duration of the experiment close to the established optimum of $45 \mathrm{~min}$ [9]. We used the reproducible effects of unilateral, repetitive, electrical stimulation of the sciatic nerve on $\mathrm{IMR}_{\mathrm{glc}}$ in the dorsal horn of the ipsilateral lumbar spinal cord of the rat for these determinations [6]. Stimulation during the $25 \mathrm{~min}$ beginning either at the time of DG injection or $25 \mathrm{~min}$ later resulted in rates of glucose utilization in the ipsilateral dorsal horn of the lumbar spinal cord that were $105 \%$ and $56 \%$, respectively, greater than those of the contralateral unstimulated control side. Attempts to decrease the residual DG in the animal by exchange blood transfusion resulted in only small $(\sim 10 \%)$ reductions in the relative effect; metabolic trapping of the first tracer during the second experimental condition remained significant.

Male, Sprague--Dawley rats $(300-430 \mathrm{~g})$ (Taconic Farms, Germantown, NY, USA), fasted for $1416 \mathrm{~h}$. were anesthetized with sodium pentobarbital $(45 \mathrm{mg} / \mathrm{kg}$, i.p.), and polyethylene catheters were inserted bilaterally into femoral arteries and veins. Anesthesia was maintained at the level of extinction of the corneal reflex with 
sodium pentobarbital (i.v.) as needed. Body temperature was maintained at $37.5^{\circ} \mathrm{C}$ by means of a heat lamp. Arterial blood pressure, arterial blood $\mathrm{pH}, p \mathrm{O}_{2}, p \mathrm{CO}_{2}$, and hematocrit were monitored during the experiment; the mean values \pm standard deviations for these variables in all experimental animals were $100 \pm 12 \mathrm{~mm} \mathrm{Hg}$, $51 \pm 2 \%, 7.44 \pm 0.05,82 \pm 6 \mathrm{~mm} \mathrm{Hg}$ and $45 \pm 5 \mathrm{~mm} \mathrm{Hg}$, respectively. There were no statistically significant differences among experimental groups in any of the physiological variables.

Sciatic nerves were exposed bilaterally and transected near the gluteus muscles; paraffin oil was pooled around the nerves to prevent desiccation. The proximal portion of the right sciatic nerve was placed on a bipolar electrode (cathode proximal) and stimulated at $15 \mathrm{~Hz}, 200$ $400 \mu \mathrm{A}$ with pulses $2 \mathrm{~ms}$ in duration. Stimulation lasted for $25 \mathrm{~min}$ beginning either at 0 time (the time of tracer injection) or $25 \mathrm{~min}$ after tracer injection. Five groups were studied: (1) no stimulation, $n=4$; (2) stimulation from 0 to $25 \mathrm{~min}, n=4$; (3) stimulation from 25 to $50 \mathrm{~min}$, $n=4$; (4) stimulation from 0 to $25 \mathrm{~min}$ with exchange blood transfusion, $n=2$; (5) stimulation from 25 to $50 \mathrm{~min}$ with exchange blood transfusion, $n=4$. The purpose of the exchange transfusion was to decrease residual DG available during the second stimulation period. Donor blood containing heparin $(30 \mathrm{U} / \mathrm{ml})$ was pumped at 4 $\mathrm{ml} / \mathrm{min}$ into the right femoral vein while radioactive blood was pumped out at the same rate from the right femoral artery into a waste container. Transfusions were started $10 \mathrm{~min}$ after tracer injection and lasted for $10 \mathrm{~min}$ resulting in at least one full exchange of total blood volume.

The period of measurement was initiated by an i.v. pulse injection of 2-deoxy-D-[1- $\left.{ }^{14} \mathrm{C}\right] \mathrm{glucose}(52.7 \mathrm{mCi} /$ mmole, DuPont-NEN, Wilmington DE, USA) $(125 \mu \mathrm{Ci} /$ $\mathrm{kg}$ b.wt.). Timed arterial blood samples $(50 \mu \mathrm{l})$ were taken throughout the 50 -min experimental time as follows: at 0 time (the time of tracer injection) blood was sampled continuously for $30 \mathrm{~s}$ followed by samples at $0.75,1,1.5,3,5,7.5,10,15,20$ and $25 \mathrm{~min}$; at $25 \mathrm{~min}$ blood was again sampled continuously for $30 \mathrm{~s}$ followed by samples at $25.75,26,26.5,28,30,32.5,35,40,45$ and $50 \mathrm{~min}$. This sampling schedule was designed to simulate a sequential double label procedure. All rats were given $2 \mathrm{ml}$ of donor blood at $20 \mathrm{~min}$. At $50 \mathrm{~min}$ rats were killed with sodium pentobarbital (i.v.), and the lower thoracic to upper sacral spinal cord was quickly removed and frozen in isopentane $\left(-45^{\circ} \mathrm{C}\right)$. Serial cryostat sections, 20 $\mu \mathrm{m}$ thick, were prepared for autoradiography [15] on OMC- 1 film (Eastman Kodak Co., Rochester, NY, USA). Concentrations of ${ }^{14} \mathrm{C}$ in the medial portions of lamina 2-6 of the dorsal horn and lamina 7-9 of the ventral horn in alternate sections through the lumbar
A.

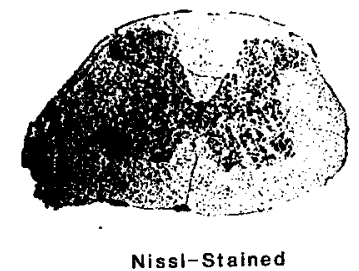

C.

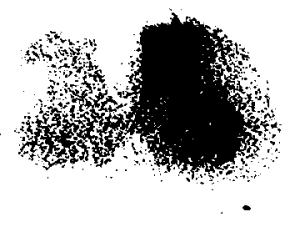

Stimulated 0-25 min.

E

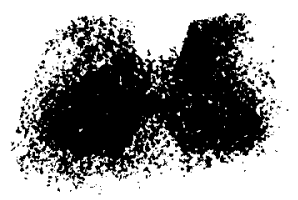

Stimulated 25-50 min.
B.

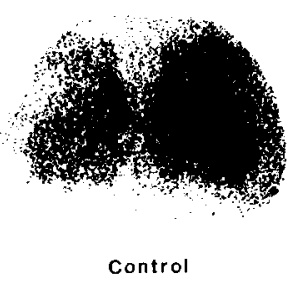

D.

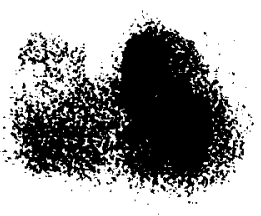

Stimulated 0-25 min. Transfused

F.

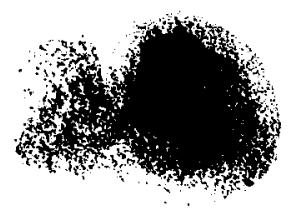

Stimulated 25-50 min. Transfused
Fig. 1. Typical $\left[{ }^{14} \mathrm{C}\right]$ deoxyglucose autoradiograms of sections of lumbar spinal cord illustrating each experimental condition (B-F) as indicated. A: a thionin-stained section of the lumbar spinal cord. Right side is on the right.

spinal cord were determined by image analysis of the autoradiograms (M1, Imaging Research Inc., St. Catharines, Ontario, Canada). Values for $\mathrm{IMR}_{\mathrm{glc}}$ were calculated by the operational equation of the DG method [15]. Each regional $\mathrm{IMR}_{\mathrm{glc}}$ is the mean value for 18-24 sections of lower lumbar cord. Side-to-side differences were analyzed by paired $t$-tests. Comparisons of side-to-side differences between groups were statistically analyzed by analysis of variance. With each data set subjected to three comparisons, effects were considered statistically significant with $P<0.017$.

Electrical stimulation of one sciatic nerve, regardless of the period of stimulation, increased $\mathrm{IMR}_{\mathrm{glc}}$ in the ipsilateral dorsal but not in the ventral horn of the lumbar spinal cord (Fig. 1, Table I). Stimulation of the sciatic nerve beginning at the time of DG injection ( 0 time) and continuing for $25 \mathrm{~min}$ resulted in a $105 \%(P<0.001$, paired $t$-test) increase in $\mathrm{IMR}_{\mathrm{glc}}$ in the ipsilateral dorsal horn above that of the contralateral control side (Table I). When stimulation was during the second half of the experimental interval (i.e. from $25-50 \mathrm{~min}$ ), $\mathrm{IMR}_{\mathrm{glc}}$ in the ipsilateral dorsal horn was still statistically significantly increased over the contralateral control side by $56 \%$ $(P<0.001$, paired $t$-test). Comparison of the side-to-side differences in $\mathrm{IMR}_{\mathrm{glc}}$ in the dorsal horn between animals 
TABLE I

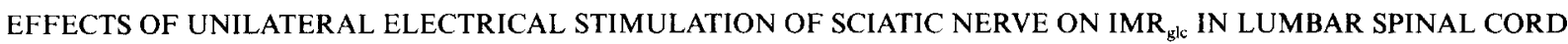

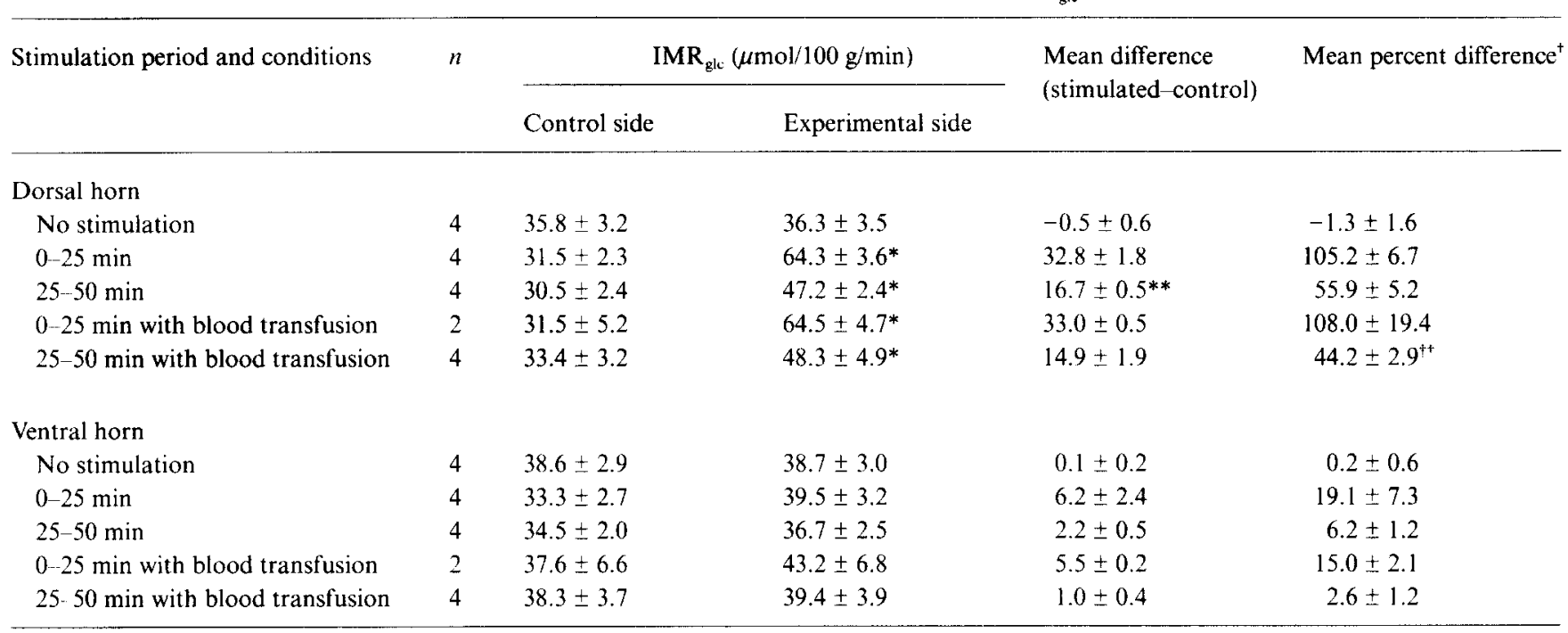

Values are the means \pm S.E.M. for the number of animals indicated.

* Statistically significantly different from the control side, $P<0.01$; paired $t$-test.

**Statistically significantly different from the difference between control and stimulated from $0-25 \mathrm{~min}, P<0.001$.

${ }^{\dagger}$ Percent differences are means of individual percent differences and not percent differences between the means.

${ }^{+}$Statistically significantly less than that of the rats stimulated from $25-50 \mathrm{~min}$ but not transfused, $P<0.05$ (one-tailed $t$-test).

stimulated from 0-25 min and 25-50 min (Table I) shows that while both periods of stimulation resulted in significant effects, the effects of stimulation during the first 25 min were statistically significantly greater than those of the stimulation during $25-50 \mathrm{~min}(P<0.001$, analysis of variance).

In an attempt to reduce residual blood and tissue levels of free DG during the second period (i.e. from 25-50 $\mathrm{min}$ ), rats were subjected to exchange blood transfusions between 10 and $20 \mathrm{~min}$ after the pulse of $\left[{ }^{14} \mathrm{C}\right] \mathrm{DG}$, well after the peak of DG in plasma. Plasma $\left[{ }^{14} \mathrm{C}\right] \mathrm{DG}$ levels were reduced by the transfusions, and the percent effect of stimulation from $25-50 \mathrm{~min}$ on $\mathrm{IMR}_{\mathrm{glc}}$ in the dorsal horn was statistically significantly smaller in the rats which received the exchange blood transfusion as compared to those which were not transfused (Table 1).

The design of a sequential double label autoradiographic DG study depends on adequate separation of the signals from the two tracers and separation of the metabolic effects of the two conditions. Separation of the tracers in the autoradiographic process can be achieved by the use of optimal ratios of ${ }^{14} \mathrm{C}$ to ${ }^{3} \mathrm{H}$ activity and mylar film, which absorbs the lower energy $\beta$-particles of ${ }^{3} \mathrm{H}$ with minor attenuation of the ${ }^{14} \mathrm{C}$ signal $[5,7]$. Separation of the two conditions, however, is complicated by restrictions of the DG method and the slow clearance of free DG from tissues and plasma. The method requires that the product, DG-6-P, remains trapped in the tissue for the duration of the experiment, but by $60 \mathrm{~min}$ after a pulse some loss of product occurs in the rat [10]. We tried, therefore, to restrict the total experimental interval to $50 \mathrm{~min}$ which is close to the established optimum of 45 $\min [9]$. There were, therefore, $25 \mathrm{~min}$ allowed for each of the two experimental conditions, i.e. injection of the first tracer at time 0 and the second tracer at $25 \mathrm{~min}$. A potential source of error is in the calculation of the integrated specific activity of tissue DG at $25 \mathrm{~min}$ after injection of the second DG tracer. This calculation depends on the estimated half-life ( $T_{1 / 2}$ of tissue DG which is normally about $2.4 \mathrm{~min}$ [15]. If, however, the $T_{1 / 2}$ of DG in the tissue under the experimental conditions is reduced $\left(T_{1 / 2}\right.$ $\rightarrow 0 \mathrm{~min}$ ) or prolonged ( $T_{1 / 2} \rightarrow 5 \mathrm{~min}$ ), then the error in the calculated integrated specific activity of DG in grey matter at $25 \mathrm{~min}$ would range from $-7 \%$ to $+10 \%$, respectively [14].

In the present studies we used only a single label with the $\left[{ }^{14} \mathrm{C}\right] \mathrm{DG}$ injected at 0 time because our goal was to examine the effect of the second experimental condition from $25-50 \mathrm{~min}$ on the metabolic response produced with the residual first tracer. In the case of stimulation from 0-25 min, the mean percent difference in $I_{M R}$ ic in the dorsal horn between the stimulated and control sides was $105 \%$, while in the case of stimulation during the second $25 \mathrm{~min}$ it was $56 \%$, approximately half the effect produced by stimulation during the first $25 \mathrm{~min}$ (Fig. 1, Table I). The difference in the magnitude of the effects of 


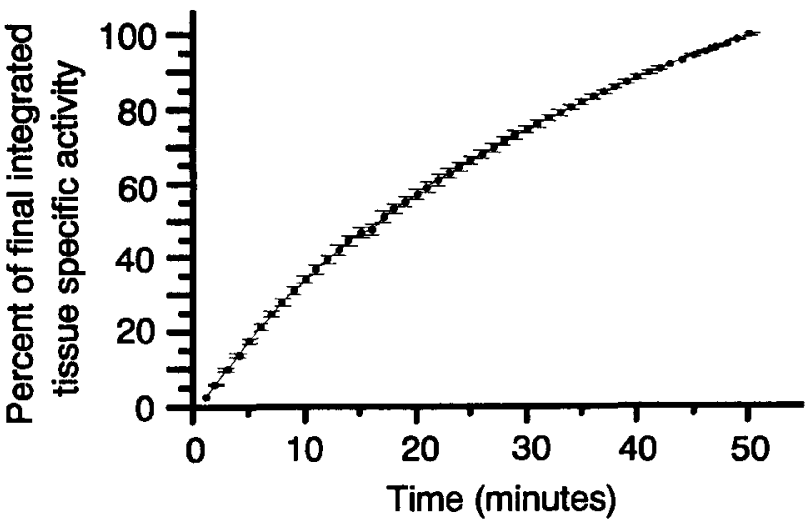

Fig. 2. Time course of the integrated specific activity of DG in grey matter as a percent of the final value at $50 \mathrm{~min}$. Each point is the mean \pm S.E.M. of 4 experiments.

stimulation during the first and second periods on $\mathrm{IMR}_{\mathrm{glc}}$ can be related to the differences in the magnitudes of the integrated tissue DG specific activities to which the brain is exposed during these two time intervals, as predicted by the model for the behavior of DG in brain. Based on this model, the values of the fitted rate constants for grey matter [15], and the time courses of the measured plasma levels of glucose and DG, the integrated tissue specific activity of DG can be calculated over the entire time course for each experiment. At 25 min, the integrated tissue specific activity for DG is $67 \%$ of the final value, whereas the tissue DG specific activity integrated from $25-50 \mathrm{~min}$ is approximately $33 \%$ of the final value (Fig. 2). The model, therefore, predicts that during the interval from $25-50 \mathrm{~min}$ following a pulse injection, the amount of DG available for phosphorylation is about $50 \%$ of the amount available during the interval from $0-25 \mathrm{~min}$; this prediction is consistent with our results (Table I) in which the effect of stimulation from $25-50$ min on $I M R_{\text {glc }}$ in the dorsal horn is approximately $50 \%$ of the effect of stimulation from 0-25 min.

Effects of residual DG have been observed in studies of auditory stimulation in guinea pigs [16], visual stimulation in monkeys [3], and somatosensory stimulation in rats [2], but the magnitude of these effects were not quantified. Solutions to this problem have been proposed. Redies et al. $[11,13]$ used a model-dependent mathematical approach in their sequential 45 -min intervals for the two tracers, i.e. total experimental period of $90 \mathrm{~min}$. They used a model which included loss of product and an operational equation for $\mathrm{IMR}_{\mathrm{glc}}$ that corrects the results obtained with the first tracer for both loss of labeled product and superimposed effects of the second condition on the estimated IMR $\mathrm{glc}_{\text {glc }}$ The limitation of this approach is that its accuracy depends entirely on the valid- ity of the model and the estimated values for the rate constants. Friedman et al. [5] have attempted to optimize the experimental intervals by allowing $35 \mathrm{~min}$ for clearance of the first tracer followed by a 10-min interval for the second tracer and second condition. Although this approach stays within the optimal 45-min total experiment time and, therefore, circumvents problems of loss of product, the accuracy of determinations of $\mathrm{IMR}_{\mathrm{glc}}$ with a 10-min experimental interval is heavily dependent on the accuracy of the values of the rate constants [14].

In the present study we tried to reduce the level of first tracer available for phosphorylation during the second experimental period by replacing the experimental animal's blood with donor blood. The exchange of $40 \mathrm{ml}$ of blood (equivalent to the entire blood volume) did increase the clearance of DG from the plasma; at $50 \mathrm{~min}$ plasma levels were about $33 \%$ below those of matched controls. The mean percent increase in IMR glc in the dorsal horn during stimulation from 25-50 min (Table I) was reduced in the transfused animals, i.e. $44 \%$ as compared with $56 \%$, but the effects of the transfusion were insufficient to eliminate the effect of the second condition in a double label experiment. The most likely explanation for the relative ineffectiveness of the blood exchange is that it is the tissues, e.g. liver, muscle, fat etc., that serve as a reservoir from which free DG is delivered to the blood and subsequently to the brain. It is possible that more extensive exchanges of blood might have more significant effects. The results of this study indicate, however, that the effect of the second experimental interval on $\mathrm{IMR}_{\mathrm{glc}}$ determined with the first tracer is substantial and that exchange blood transfusion does not resolve this problem.

1 Altenau, L.L. and Agranoff, B.W., A sequential double-label 2deoxyglucose method for measuring regional cerebral metabolism, Brain Res., 153 (1978) 375-381.

2 Ciricillo, S.F., Jasper, M.P., Gonzalez, M.F. and Sharp, F.R., Long experimental durations are required for double label. $\left[{ }^{14} \mathrm{C}\right]-$ and $\left[{ }^{3} \mathrm{H}\right] 2$-deoxyglucose autoradiographic methods, Brain Res., 564 (1992) 171-175.

3 Friedman, H.R., Bruce, C.J. and Goldman-Rakic, P.S., Resolution of metabolic columns by a double-label 2-DG technique: interdigitation and coincidence in visual cortical areas of the same monkey, J. Neurosci., 9 (1989) 4111-4121.

4 Friedman, H.R., Bruce, C.J. and Goldman-Rakic, P.S., A sequential double-label ${ }^{14} \mathrm{C}$ - and ${ }^{3} \mathrm{H}-2-\mathrm{DG}$ technique: validation by doubledissociation of functional states. Exp. Brain. Res., 66 (1987) 543554.

5 Friedman, H.R., Bruce, C.J. and Goldman-Rakic, P.S. Doublelabel $\left[{ }^{3} \mathrm{H}\right] 2$-deoxyglucose and $\left[{ }^{14} \mathrm{C}\right] 2$-deoxyglucose method for mapping brain activity underlying two experimental conditions in the same animal. In: Methods in Neuroscience, Vol. 3, Academic Press, NY, 1990, pp. 389-412. 
6 Kadekaro, M., Crane, A.M. and Sokoloff, L., Differential effects of electrical stimulation of sciatic nerve on metabolic activity in spinal cord and dorsal root ganglion in the rat, Proc. Natl. Acad. Sci. USA, 82 (1985) 6010-6013.

7 Livingston, M.S. and Hubel, D.H., Effects of sleep and arousal on the processing of visual information in the cat, Nature, 291 (1981) 554-561.

8 Lyon, M.J., Smith, C.B., Agranoff, B.W. and Sokoloff, L., Residual effects of tracer in sequential double label deoxyglucose studies, Soc. Neurosci. Abstracts, 17 (1991) 473.

9 Mori, K., Schmidt, K., Jay, T., Palombo, E., Nelson, T., Lucignani, G., Pettigrew, K., Kennedy, C. and Sokoloff, L., Optimal duration of experimental period in measurement of local cerebral glucose utilization with the deoxyglucose method, J. Neurochem., 54 (1990) 307-319.

10 Nelson, T., Dienel, G.A., Mori, K., Cruz, N.F. and Sokoloff, L., Deoxyglucose-6-phosphate stability in vivo and the deoxyglucose method: response to comments of Hawkins and Miller, J. Neurochem., 49 (1987) 1949-1960.

11 Redies, C., Diksic, M., Evans, A.C., Gjedde, A. and Yamamoto, Y.L., Double-label autoradiographic deoxyglucose method for se- quential measurement of regional cerebral glucose utilization, Neuroscience, 22 (1987) 601-619.

12 Redies, C., Diksic, M. and Riml, H., Functional organization in the ferret visual cortex: a double-label 2-deoxyglucose study, J. Neurosci., 10 (1990) 2791-2803.

13 Redies, C. and Gjedde, A., Double-label and conventional deoxyglucose methods: a practical guide for the user, Cerebrovasc. Brain Metab. Rev., 1 (1989) 319-367.

14 Sokoloff, L., Mapping local functional activity by measurement of local cerebral glucose utilization in the central nervous system of animals and man, The Harvey Lectures, Series 79, (1985) 77-143.

15 Sokoloff, L., Reivich, M., Kennedy, C., Des Rosiers, M.H., Patlak, C.S., Pettigrew, K.D., Sakurada, O. and Shinohara, M., The $\left[{ }^{14} \mathrm{C}\right]$ deoxyglucose method for measurement of local cerebral glucose utilization: theory, procedure, and normal values in the conscious and anesthetized albino rat, J. Neurochem., 28 (1977) 897 916.

16 Webster, W.R., Serviere, J., Martin, R. and Hartley, E., Tonotopic bands produced by tones commenced long after 2-deoxyglucose injection, Neurosci. Lett., 40 (1983) 281-286. 